\title{
The Interplay of Attention and Emotion: Top-down Attention Modulates Amygdala Activation in Psychopathy
}

\author{
Christine L. Larson ${ }^{1}$, Arielle R. Baskin-Sommers ${ }^{2}$, Daniel M. Stout ${ }^{1}$, Nicholas L. \\ Balderston ${ }^{1}$, John J. Curtin ${ }^{2}$, Douglas H. Schultz ${ }^{1}$, Kent A. Kiehl ${ }^{3}$, and Joseph P. Newman ${ }^{2}$ \\ ${ }^{1}$ Department of Psychology, University of Wisconsin-Milwaukee \\ 2Department of Psychology, University of Wisconsin-Madison \\ ${ }^{3}$ Mind Research Network and Department of Psychology, University of New Mexico
}

\begin{abstract}
Psychopathic behavior has long been attributed to a fundamental deficit in fear that arises from impaired amygdala function. Growing evidence demonstrates that fear potentiated startle (FPS) and other psychopathy-related deficits are moderated by focus of attention but, to date, no work on adult psychopathy has examined attentional modulation of the amygdala, or concomitant recruitment of relevant attention-related circuitry. Consistent with previous FPS findings, here we report that psychopathy-related differences in amygdala activation appear and disappear as a function of goal-directed attention. Specifically, decreased amygdala activity was observed in psychopathic offenders only when attention was engaged in an alternative goal-relevant task prior to presenting threat-relevant information. Under this condition, psychopaths also exhibited greater activation in selective attention regions of the lateral prefrontal cortex (LPFC) than nonpsychopaths, and this increased LPFC activation mediated psychopathy's association with decreased amygdala activation. In contrast, when explicitly attending to threat, amygdala activation in psychopaths did not differ from non-psychopaths. This pattern of amygdala activation highlights the potential role of LPFC in mediating the failure of psychopathic individuals to process fear and other important information when it is peripheral to the primary focus of goal-directed attention.
\end{abstract}

Psychopathy is a common and severe psychopathological disorder affecting approximately $1 \%$ of the general population and 15-25\% of incarcerated male offenders (Hare, 1996; Neumann \& Hare, 2008). Despite psychopathic individuals' good intelligence and an absence of Axis I psychopathology (aside from substance abuse; Hart \& Hare, 1989), they display an inability to form genuine relationships with parents, teachers, friends, or lovers; limited and superficial affective processing especially with respect to anticipatory anxiety and remorse; an impulsive behavioral style involving a general failure to evaluate anticipated actions and inhibit the inappropriate ones; and a chronic antisocial lifestyle that entails great costs to society as well as for the affected individual (e.g., incarceration; Cleckley, 1941). While both affective and behavioral characteristics are important elements of psychopathy, the affective deficits have traditionally been considered the root cause of the psychopath's problems.

Affective deficits in psychopathy have most often been understood in the context of the lowfear model (Lykken, 1957), which posits that the psychopath's deficit is mediated by an amygdala-based deficiency (Blair, 2003; Marsh \& Cardinale, in press; Patrick, 1994; Viding

Corresponding author: Christine Larson, University of Wisconsin-Milwaukee, Department of Psychology, PO Box 413, Milwaukee, WI 53201. Phone: 414-229-4996. larsonc1@uwm.edu. 
et al., 2012). In adult samples, while there is a some neuroimaging evidence that suggests psychopathic individuals display less amygdala activation than controls during aversive conditioning, moral decision-making, social cooperation, and memory for emotionally salient words (Birbaumer et al., 2005; Glenn, Raine, \& Schug, 2009; Harenski, Harenski, Shane, \& Kiehl, 2010; Kiehl et al., 2001; Rilling et al., 2007) there are also results indicating that psychopathic individuals display greater amygdala reactivity when viewing emotionally salient scenes and emotionally evocative faces (Carre, Hyde, Neumann, Viding, \& Hariri, 2012; Muller et al., 2003). Thus, existing research in psychopathy does not indicate the presence of a reliable amygdala deficit, though such deficits may be revealed for psychopathic individuals under specific experimental circumstances.

Given the potential inconsistency in psychopathy-related amygdala deficiency, it may be that this traditional view of a primary amygdala deficit in psychopathy undervalues the role that cognitive-affective and cortical-subcortical brain interactions have in modulating the complex etiological and phenotypic manifestation of psychopathy. Recent theoretical and empirical models of psychopathy have attempted to integrate cognitive and affective processes and their influence on prototypic psychopathic behavior (Blair, 2007; Kiehl, 2006; Moul, Killcross, \& Dadds, 2012; Newman \& Baskin-Sommers, 2011). Hence, as deficits in a number of cognitive processes have been implicated in these formulations, there is increasing empirical support for the hypothesis that psychopaths have a core deficit in attention, particularly the adaptive deployment of selective attention (see Newman \& Baskin-Sommers, 2011 for review).

Work in this area indicates that psychopaths are impaired in the ability to alter top-down goal-directed behavior to incorporate information from salient bottom-up stimuli (including threat cues), and that this inability to modulate behavior results directly from a failure to reallocate attention away from the goal-relevant task toward salient, but task-irrelevant, stimuli (Patterson \& Newman, 1993). Moreover, the affective dysfunction observed in psychopaths can be explained by this deficit in adaptively switching between top-down and bottom-up deployment of selective attention. For instance, psychopathic offenders display poor passive avoidance and weak electrodermal responses to punishment cues when they are focused on approach-related goals, but these differences disappear when avoidance learning takes precedence (Arnett, Smith, \& Newman, 1997; Newman \& Kosson, 1986). Similarly, psychopaths display normal fear potentiated startle (FPS) when explicitly attending to threat cues, but the same threat cues elicit significantly smaller startle responses in psychopaths than non-psychopaths when attention is already engaged by another stimulus or task (Baskin-Sommers, Curtin, \& Newman, 2011; Newman, Curtin, Bertsch, \& BaskinSommers, 2010). Thus, across these diverse experimental paradigms, psychopathic offenders display normal responses to affective information when it is part of their primary task, but their reactions to the same affective stimuli are deficient if they have allocated attention to other goal-relevant stimuli (see Newman \& Baskin-Sommers, 2011 for review).

Synthesizing these findings, Baskin-Sommers et al. (2011) proposed that an early attention bottleneck is the proximal mechanism underlying deficient emotion reactivity in psychopathy (see also Newman \& Baskin-Sommers, 2011). The rationale for the attention bottleneck stems from models that characterize early selective attention as a "fixed bottleneck" that processes information in serial and once established, blocks the processing of peripheral information that is not goal relevant (Driver, 2001). Such a bottleneck would confer an advantage for psychopaths in filtering potential distracters, but at the cost of undermining the ability to attend to multiple ongoing streams of information. Ultimately, this trade-off would result in a tendency to overlook potential threat and other important information unless it is directly related to their goal-directed focus of attention. Thus, according to the attention bottleneck model, psychopaths are insensitive to threat cues not 
because they are incapable of fear responses, but because their failure to reallocate attention to affective stimuli while engaged in goal-directed behavior renders them oblivious to these affective cues.

To directly test the attention bottleneck hypothesis, Baskin-Sommers et al. (2011) measured FPS during an instructed fear paradigm that crossed focus of attention (Threat versus Alternative focus) with early versus late presentation of goal-relevant cues. As predicted, psychopaths' deficit in FPS was non-existent under conditions that focused attention on the threat-relevant dimension of the stimuli (i.e., Threat-Focus Conditions), but was pronounced when threat-relevant cues were peripheral to their primary focus of attention (i.e., Alternative Focus Conditions). More specifically, the psychopathic deficit was only apparent in the Early Alternative Focus Condition, in which threat cues were presented after the alternative goaldirected focus was established. That is, psychopathic individuals displayed a deficit in threat processing when their attention was previously engaged in a goal-directed focus and did not display a threat-processing deficit under any other circumstances.

Despite specific support for the attention bottleneck model and substantial evidence regarding the pivotal role of attention in the affective and inhibitory deficits associated with psychopathy (Blair \& Mitchell, 2009; Newman \& Baskin-Sommers, 2011), investigators have yet to examine the influence of this early selective attention bias on emotion processing in psychopathy using neuroimaging. Given the prominence of the low fear model of psychopathy, much of the extant imaging work in this population has examined amygdala functioning; however, only one study to date has examined amygdala activation to threatrelated stimuli as a function of attention, albeit in children with callous-unemotional traits rather than psychopathy per se (White et al., 2012). And, no study has specifically assessed recruitment of the amygdala using a task explicitly designed to elicit psychopaths' early selective attention deficits. Furthermore, despite the amygdala's prominence in most etiological models of psychopathy, the neuroimaging literature in this area is actually quite small yields somewhat mixed conclusions (see Koenigs, Baskin-Sommers, Zeier, \& Newman, 2011 for review). While there are a number of factors (e.g., sample, experimental context) that may influence the reliability of a psychopathy-related amygdala deficit, one possibility is that these inconsistencies may be explained by attentional engagement. For example, given the association between FPS and amygdala activation (Davis, Falls, Campeau, \& Kim, 1993; Grillon, Ameli, Goddard, Woods, \& Davis, 1994) the BaskinSommers et al. (2011) FPS findings raise the possibility that amygdala dysfunction in psychopathic offenders may be modulated by an early attention bottleneck. However, direct investigation is required to determine whether the precise attentional manipulations that undermine FPS in psychopathy would also be associated with psychopathyrelated deficits in amygdala activation.

In addition to assessing whether manipulating attentional engagement modulates amygdala activation in psychopathy, neuroimaging offers the opportunity to more specifically investigate recruitment of top-down attention circuitry that may instantiate the attention bottleneck evident in psychopaths. Basic neuroscience models (Bishop, 2007; Corbetta, Patel, \& Shulman, 2008; Dux, Ivanoff, Asplund, \& Marois, 2006) and models of psychopathy (Blair, 2003; Kiehl, 2006) highlight the role of the prefrontal cortices (e.g., orbitofrontal, lateral prefrontal) in directing attention towards task-relevant information and inhibiting processing of salient distracting information. Notably, recent work has explicitly identified LPFC as the site of an information processing bottleneck (Dux et al., 2006), leading Newman and Baskin-Sommers (2011) to speculate that regions of the LPFC may be central to the early attention bottleneck operating in psychopathy. Moreover, engagement of the LPFC is thought to be specifically necessary to override the amygdala-based automatic 
processing of threat related information (Davidson, 2000; Dolcos \& McCarthy, 2006; Ochsner et al., 2004; Siegle, Steinhauer, Thase, Stenger, \& Carter, 2002). Thus, we hypothesize that LPFC in particular may mediate psychopaths' deficits in processing multiple streams of information. Although this LPFC-mediated attention bottleneck model provides a promising and potentially crucial perspective on psychopathy, more direct evidence concerning the neural underpinnings of abnormal attentionemotion interactions in psychopathy is required to substantiate the model.

The primary aim of this study was to address the paucity of neuroimaging data available to specify the neural mechanisms mediating the attention-related modulation of emotion processing in psychopathy. Toward this end, we administered the instructed fear paradigm developed by Baskin-Sommers et al. (2011) in the context of a functional magnetic resonance imaging study. More specifically, by employing the same experimental manipulations that enabled Baskin-Sommers and colleagues to specify the attention bottleneck, we aimed to identify the neural correlates associated with the early attention bottleneck. Paralleling results from the Baskin-Sommers et al. (2011) study, we predicted that psychopathy-related abnormalities associated with the attention bottleneck would be specific to the Early Alternative Focus condition. In light of the fact that psychopathic participants displayed less FPS than controls specifically in the Early Alternative Focus condition, we predicted that psychopathy would also be associated with weaker amygdalarelated differentiation to threat and safety cues in this condition, but not in the Threat Focus or Late Alternative Focus conditions. Furthermore, stemming from the attention bottleneck model, we predicted that psychopathy would be associated with greater activation in regions of LPFC in the Early Alternative Focus condition, reflecting a strong goal-directed focus and a failure to disengage attention from the alternative focus (letter) cue when faced with a subsequent salient threat stimulus (red box). We further predicted that this activation in LPFC would mediate the reduced amygdala-related differentiation associated with psychopathy.

\section{Methods}

\section{Subjects}

Seventy-one white male prisoners from a medium security prison in Southern Wisconsin between the ages of 18 and 45 were asked to participate in this study. Elements of consent were presented individually to all participants in verbal and written form. Participants were informed that their decision to take part in the project or to refuse would have no influence on their status within the correctional system. Of the 71, 66 prisoners agreed to participate (93\%). Participants were excluded if they were: age 45 or older, currently used psychotropic medication, had clinical diagnoses of schizophrenia, bipolar disorder, or psychosis not otherwise specified (NOS), contraindications for MR scanning (metal in body, unable to lie still in scanner, history of neurological disorder or head injury, claustrophobia), scored below the 4th grade reading level on achievement tests administered by the Department of Corrections, or had an estimated IQ score of less than 70 on the Shipley Institute of Living Scale (SILS) (Zachary, 1986). Participants older than 45 years of age were excluded because the expression of psychopathic traits (i.e., impulsivity) has been found to decline with advancing age (Haprur \& Hare, 1994; Hare et al., 1990) also, some research suggests that memory and cognitive functioning begins to decline starting around age 45 (Singh-Manoux et al., 2012).

All participants were assessed using file information and a semi-structured interview that lasted approximately 60 minutes and provided sufficient information to diagnose psychopathy using the Psychopathy Checklist-Revised (PCL-R) (Hare, 2003). The PCL-R contains 20 items that are rated 0,1 , or 2 according to the degree to which a characteristic is 
present: significantly (2), moderately (1), or not at all (0). Numerous sources have documented the reliability and validity of the PCL-R (Hare, 2003).

Three participants were dropped due to poor alignment of structural and functional images, six because of movement artifact, one due to claustrophobia, six because of shock device malfunction, and one (nonpsychopath) because their amygdala activation exceeded 3 SDs from the mean. The final sample consisted of 24 psychopaths and 25 nonpsychopaths (see Table 1 for descriptive information about the sample).

\section{Instructed Fear Task}

The task consisted of four conditions, with 60 trials per condition. The task conditions crossed focus of attention and timing of goal-relevant information, yielding the Early Alternative Focus, Early Threat Focus, Late Alternative Focus, and Late Threat Focus Conditions (Fig. 1). In the two threat focus conditions, participants attended to the color of a box predicting shock administration $($ red boxes $=$ potential shock, green boxes $=$ safe, no chance of shock). In the two alternative focus conditions, participants were instructed to attend to the case of a letter stimulus and the case of the letter was unrelated to administration of electric shocks. Each of the four conditions was blocked, with the order counterbalanced across participants.

On every trial in all conditions, a fixation cross was displayed for 400 to $1200 \mathrm{~ms}$ (mean = $800 \mathrm{~ms}$ ) at the beginning of each trial. Then participants saw two stimuli presented sequentially: a box (red or green) and a letter (uppercase "N" or lowercase " $n$ "), presented sequentially. The order of stimulus appearance varied by condition. The first stimulus (either a box or a letter) appeared alone for $200 \mathrm{~ms}$, and then the second stimulus (the box or letter, whichever was not presented first) appeared concurrently with the first stimulus for another $200 \mathrm{~ms}$. Following the offset of the stimuli a blank screen appeared for $1200 \mathrm{~ms}$. After the blank screen, for $1600 \mathrm{~ms}$, a descriptive word appeared on the screen, prompting participants to respond on the basis of either the first or the second stimulus, according to the condition. In the threat-focus conditions, the word "Red" or "Green" was presented, and participants pressed one of two buttons to indicate whether the word described the color of the box during that trial. In the alternative-focus conditions, the word "Upper" or "Lower" appeared, and participants pressed one of two buttons to indicate whether the word described the case of the letter during that trial. Participants were asked to make a button box response according to the nature of each condition.

In all conditions, participants were given instructions about which stimulus was goalrelevant and which stimulus signaled threat (shock) or safety (no shock). The intensity of shocks was calibrated to participants' subjective tolerance (a procedure administered prior to the task, see Electrical Stimulation section). If a shock was presented, it occurred during the last 200 ms of the blank screen. Shocks were presented on $20 \%$ of threat trials ( 6 trials per condition).

Finally, across conditions the timing of task-relevant focus of attention (early or late) was manipulated to examine the effects of the early attention bottleneck. As mentioned above, this was accomplished by presenting the task-relevant stimulus either first or second in the trial sequence. As shown in Figure 1, the Early Alternative Focus condition is the only one that engages attention prior to presenting the threat-relevant information. As such this condition is the only one expected to reveal a psychopathy-related deficit in amygdala activation. 


\section{Electrical Stimulation}

Shocks were delivered via an AC source (Contact Precision Instruments, Boston, MA) through two $\mathrm{Ag} / \mathrm{AgCl}$ electrodes placed over the right tibial nerve over the right medial malleolus (right ankle). To control for individual differences in shock sensitivity, the intensity of shocks received during the experimental session were calibrated to the participants' individual subjective shock sensitivity. This procedure was conducted immediately prior to the start of the instructed fear paradigm. Participants were administered a series of electric shocks of increasing intensity and rated the intensity of the shock on a scale from zero (no sensation) to ten (painful but tolerable). The intensity of the shock administered reported two intensity anchors: the first intensity that they considered uncomfortable and then the maximum intensity level that they could tolerate. The series was terminated when they reached a self-reported intensity level of ten. This intensity was used for all administrations during the instructed fear task.

\section{Image Acquisition}

Data were collected on the grounds of the prison using the Mind Research Network (MRN) mobile 1.5 T Siemens Avanto scanner. The MRN mobile MRI is equipped with advanced SQ gradients (max slew rate $200 \mathrm{~T} / \mathrm{m} / \mathrm{s}, 346 \mathrm{~T} / \mathrm{m} / \mathrm{s}$ vector summation, rise time us) and a 12 element head coil (http://www.mrn.org/facilities/mobile-mri-scanning-facility). EPI echoplanar functional images were collected according to the following parameters: TR/TE (2000/39 ms, flip angle $75^{\circ}$, FOV $24 \times 24 \mathrm{~cm}, 64 \times 64$ matrix, $3.75 \times 3.75 \mathrm{~mm}$ in plane resolution, $5 \mathrm{~mm}$ slice thickness, 27 axial oblique slices). Head motion was limited using padding. Participants with motion greater than $3 \mathrm{~mm}$ were excluded from analysis.

Highresolution MPRAGE structural images were obtained to cover the whole brain with 128 $1 \mathrm{~mm}$ sagittal slices, $8^{\circ}$ flip angle and $24 \mathrm{~cm}$ FOV.

\section{fMRI Data Pre-processing and Analysis}

All fMRI data pre-processing and analysis was conducted with AFNI software (Cox, 1996). After image reconstruction, rigid-body motion correction was done in three translational and three rotational directions, with all images registered to the fifth functional image in the timeseries. The amount of motion in these directions was estimated and then included as regressors in subsequent analyses. Participants with more than $3 \mathrm{~mm}$ displacement were excluded from the final sample. MR signal was normalized to a mean of 100 (arbitrary units). Functional timeseries were deconvolved using a tent function. Mean percent signal change for images two through five following each stimulus onset was calculated. A spatial blur of $4 \mathrm{~mm}$ full width half maximum was applied and images were resampled to $1 \mathrm{~mm}^{3}$ voxels. Anatomical images for each participant were transformed to Talairach space and each functional run was warped to the Talairach-transformed anatomical image. One participant did not have usable anatomical scans so the functional images were transformed to a standard Talairach template. Threat minus safe difference scores were calculated for each condition for each subject and used as the dependent variable in all analyses.

\section{Whole Brain Group Analysis}

Our main a priori hypothesis was that psychopaths would exhibit normal levels of amygdala activation during all conditions except the Early Alternative Focus condition. To test this hypothesis we conducted an ANOVA structured to replicate the startle findings reported by Baskin-Sommers et al. (2011). This voxel-wise ANOVA compared activation between psychopaths and nonpsychopaths for the Early Alternative Focus condition against the average of the three remaining conditions, as was done in the previous startle work. Subject was included as a random factor in the model ${ }^{1}$. For all whole brain voxel-wise analyses cluster thresholding based on Monte Carlo simulations calculated with AFNI's AlphaSim 
was applied to correct for multiple comparisons. Using a voxel-based $p<.025$ and nearestneighbor selection criteria, accounting for spatial correlation, clusters greater than $562 \mathrm{~mm}^{3}$ achieved a whole-brain corrected $p$ value $<0.05$.

Subsequent post-hoc analyses (using the same cluster thresholding criteria) were designed to clarify the additional circuitry instantiating aberrant attentional processes for psychopaths in the Early Alternative Focus condition. To accomplish this, a voxel-wise t-test was calculated comparing activation for psychopaths and non-psychopaths for the Early Alternative Focus condition.

\section{Results}

\section{Amygdala Activation as Function of Attentional Focus}

As predicted by the attention bottleneck hypothesis, in the Early Alternative Focus condition psychopaths exhibited differential activation compared to nonpsychopaths in the right amygdala (peak: $x=20, y=-6, z=-13$; Fig. 2 ; see Table 2 for data presented separately for threat and safe for all four attention conditions). In this condition, in which attention was engaged in a neutral task prior to presentation of the task-irrelevant threat cue, nonpsychopaths exhibited relatively greater amygdala activation, particularly in comparison with psychopaths. Also consistent with the attention-based predictions, there was no evidence of psychopathyrelated differences in amygdala activation in the remaining three conditions (separately or combined; see Fig. 2 and Table 2).

\section{Attention-related Circuitry: Early Alternative Focus Condition}

As predicted, group differences in amygdala activation were specific to the Early Alternative Focus Condition. Thus, follow-up analyses examining attention-related circuitry focused on this condition. A whole-brain $t$-test comparing activation for psychopaths and nonpsychopaths during Early Alternative Focus revealed significant group differences in three left LPFC clusters: the inferior frontal gyrus (IFG; $-49, \mathrm{y}=14, \mathrm{z}=0$; BA 47), middle frontal gyrus (MFG; $-49, \mathrm{y}=36, \mathrm{z}=-4$; BA 47), and superior frontal gyrus (SFG; $\mathrm{x}=-23$, $y=48, z=-3$; BA 10) (Fig. 3). The direction of these effects indicates that psychopaths are recruiting neural regions in the dorsolateral (SFG/BA 10) and mid-ventrolateral PFC (mVLPFC; IFG and MFG/BA 47) that are associated with selective attention to a greater extent than nonpsychopaths.

To aid in interpreting the interaction between psychopathy status and recruitment of LPFC regions, simple regressions were conducted between LPFC regions and the amygdala within each group separately ${ }^{2}$. LPFC activation significantly predicted amygdala activation in psychopaths but not in non-psychopaths for all three LPFC regions (Fig. 4). For psychopaths the $r$-values for the IFG, MFG, and SFG were -.44, -.73, and -.49 (all $p$ 's <.05), respectively. For the non-psychopaths the corresponding IFG, MFG, and SFG $r$-values were $.38,-.05$, and -.14 (all $p$ 's $>.05$ ). A test of the significance of the difference between independent r's (Cohen \& Cohen, 1983) revealed that the magnitude of the LPFC-amygdala correlations was significantly different for the two groups for the two clusters in mVLPFC/ BA 47, IFG and MFG ( $p=.004$ for both), but not for the dorsolateral SFG cluster $(p=.19)^{3}$.

\footnotetext{
${ }^{1}$ Analyses of the amygdala data were also conducted separately for each of the four conditions. These data are presented in the supplementary materials.

${ }^{2}$ For consistency, the amygdala cluster used in these correlations was also extracted from the between groups $t$-test for the Early Alternative Focus condition. Although slightly more ventral, the amygdala cluster yielding significant group differences for this contrast was largely overlapping with that from the initial a priori ANOVA described above (peak: $x=19, y=-7, z=-9$ ). The cluster size for the original ANOVA was $1211 \mathrm{~mm}^{3}$ and for the Early Alternative Focus condition t-test the cluster size was $1257 \mathrm{~mm}^{3}$. A conjunction analysis revealed an overlap of $915 \mathrm{~mm}^{3}$.
} 
Finally, we examined whether LPFC activation mediated the relationship between psychopathy and amygdala activation. To test mediation, we used an SPSS macro designed to implement a simultaneous multiple mediator bootstrapping model (Preacher \& Hayes, 2004, 2008). Two mediator models were run, once with the LPFC regions combined and once with the three regions (IFG, SFG, MFG) as separate mediators, to examine the total and direct effects of psychopathy on amygdala activation, as well as the total and specific indirect effects of psychopathy on amygdala activation through the prefrontal regions. All models were based on 2,000 samples, producing $95 \%$ bias-corrected and accelerated confidence intervals that did not contain zero. The regression models indicated that: 1) psychopathy significantly predicted LPFC activation (Combined LPFC: $B=.07, S E B=$ $0.01, t=4.51, p<.001$; IFG: $B=.09$, SEB $=0.02, t=3.87, p<.001$; SFG: $B=0.05$, SEB $=$ $0.02, t=2.48, p=.01$; MFG: $B=0.10, S E B=0.03, t=3.84, p<.001) ; 2)$ there were significant direct effects of LPFC activation on amygdala activation, but only for the combined LPFC and the specific mVLPFC/BA 47 region (Combined LPFC: $B=-1.02$, SEB $=0.31, t=-3.33, p<.001$; IFG: $B=.28, S E B=0.24, t=1.16, p=.25$; SFG: $B=-.32$, SEB $=$ $0.29, t=-1.09, p=.28$; MFG: $B=-0.80, S E B=0.23, t=-3.43, p<.001) ; 3)$ there was a significant total effect of psychopathy on amygdala activation $(B=-0.09, S E B=0.03, t=$ $-2.35, p=.02)$; 4 ) the direct effect of psychopathy status on amygdala activation was not significant $(B=-0.02, S E B=0.04, t=-.57, p=.57)$; and 5) the indirect effects of psychopathy on amygdala through the combined $\operatorname{LPFC}(z=-2.22, p=.03)$ region and the mVLPFC/BA $47(z=-2.63, p=.01)$ were significant, whereas the indirect effects of IFG $(z=$ $-1.16, p=.25)$ and SFG $(z=-1.04, p=.30)$ were not significant. The overall regression model was significant $\left(F[4,44]=7.26, R_{a d j}^{2}=.34, p<.001\right)$. Together, this pattern of results indicates full mediation when considering the impact of combined LPFC region, and more specifically mVLPFC/BA 47, on the association between psychopathy and amygdala activation.

\section{Discussion}

In light of growing evidence that attention moderates the core behavioral and affective deficits associated with psychopathy, we attempted to extend these findings to amygdala dysfunction because of its prominence in prevailing models of psychopathy (Blair, 2007; Glenn et al., 2009; Patrick, 2007). Paralleling results for fear-potentiated startle (BaskinSommers et al., 2011), we found unambiguous evidence that psychopaths' amygdala dysfunction can be moderated by focus of attention. Moreover, we found that the association between psychopathy and amygdala activation was mediated by regions of LPFC with established links to top-down attention. Thus, in conjunction with previous findings, the current results provide strong evidence for the crucial role of top-down attention in moderating the impact of bottom-up emotion and inhibitory cues among psychopathic offenders.

\section{The role of attention on psychopathy-related differences in amygdala activation}

As predicted by the attention bottleneck model, psychopathy-related deficits in amygdala activation were specific to experimental conditions that engaged attention in goal-relevant processing prior to presenting threat-relevant information. Once focused on goal-relevant stimuli (i.e., letter stimulus), psychopathic compared to nonpsychopathic offenders displayed significantly less amygdala activation to subsequently presented threat stimuli, indicating impaired recruitment of task-relevant regions during serial information

\footnotetext{
${ }^{3}$ We also assessed whether group moderated the association between LPFC and amygdala activation using moderated regression (Aiken \& West, 1991). After entering Group and mean-centered LPFC activation into the model predicting amygdala activation (separately for each LPFC cluster), the interaction between Group and LPFC was significant for IFG $(\beta=-.40, p=.004)$, and MFG $(\beta$ $=-.29, \mathrm{p}=.04)$, but not SFG $(\beta=-.15, \mathrm{p}=.29)$.
} 
processing. Also as predicted, this deficit disappeared when threat cues were presented prior to establishing a goaldirected focus of attention (i.e., late alternative focus) and when the conflict between processing goal-relevant and threat-relevant stimuli was eliminated (i.e., under threat-focused conditions). Thus, the current findings corroborate the crucial role of attention in moderating the impact of bottom-up emotion on psychopathic offenders, and further suggest that this attentional moderation is specifically influencing engagement of the amygdala.

Also addressing the effects of attention on threat processing, albeit in youth with moderate levels of callous-unemotional traits rather than adult psychopathic offenders, White and colleagues (2012) manipulated attentional load in a primary task while presenting taskirrelevant faces. More specifically, White et al. presented fearful and neutral faces (i.e., goalirrelevant stimuli) that were flanked by lines that varied in vertical orientation. Participants were instructed to indicate whether or not the lines were parallel (i.e., goalrelevant stimuli), and attentional load was manipulated by altering the difficulty of this discrimination. Consistent with the attention bottleneck proposal, youth with elevated callous/unemotional traits displayed less affect-mediated amygdala activation to the taskirrelevant fearful faces than controls when primary task attentional load was low, though no group difference was found in the high load condition. White and colleagues interpreted the absence of group differences in the high load condition as inconsistent with the bottleneck hypothesis. However, the lack of group difference in the high load condition is in keeping with work demonstrating that even in healthy individuals, when attention is fully occupied by high perceptual load, processing of peripheral cues is minimal (Lavie, Hirst, de Fockert, \& Viding, 2004). Thus, the opportunity to observe individual differences, particularly in amygdala activation, under such conditions is necessarily limited (Bishop, Jenkins, \& Lawrence, 2007; Hsu \& Pessoa, 2007; Pessoa, Padmala, \& Morland, 2005). In light of such findings, White et al.'s results for the low-load condition appear to provide a more sensitive evaluation of attention-related effects on amygdala activation. Overall then, the pattern of psychopathy-related results showing deficient amygdala activation to peripheral emotion stimuli when engaged in another goal, appears to be consistent with the attention bottleneck model (see Sadeh \& Verona, 2008).

Together these studies provide initial support for attentional moderation of emotion processing in psychopathy and related traits. Focusing on the current study, as noted above, the pattern of psychopathy-related differences in amygdala activation corresponded precisely to our a priori hypotheses. At a more general level, however, the fact that participants, including nonpsychopaths, failed to display significantly more amygdala activation on threat trials than on safe trials across many of the attention conditions was not expected (see Table 2). Nevertheless, subsequent investigation of this issue reveals a number of theoretical and methodological considerations that put these findings in perspective and diminish concern regarding their implications for the current results. First, a number of other investigations of cognitive-emotion interactions in psychopathy and other antisocial samples (e.g., Marsh et al., 2011; Passamonti et al., 2010; White et al., 2012) report negative amygdala activations. Second, the relatively weak amygdala activation found among both psychopaths and nonpsychopaths in our instructed fear paradigm is consistent with results from a recent meta-analysis by Mechias, Etkin and Kalisch (2010), which failed to find consistent amygdala activation in healthy controls across an array of instructed fear paradigms. Third, there is growing evidence that attentional load dampens amygdala activation (Bishop et al., 2007; Hsu \& Pessoa, 2007; Pessoa et al., 2005). With this in mind, it is worth noting that the threat stimuli in our study were embedded in a cognitive task that required participants to (a) maintain a top-down set to focus on particular stimuli, (b) categorize the stimuli, (c) preserve the categorization in working memory, and (d) make a rapid decision at the end of each trial. Thus, relative to tasks that involve passive viewing of 
emotion stimuli, our study involved significant cognitive demands that may have played a key role in reducing amygdala activation. Despite these constraints on overall amygdala activation, we propose that the relative level of amygdala activation in this study provides a valid estimate of fear magnitude. In support of this proposal, we note that previous research employing the same paradigm yielded nearly identical psychopathy-related differences in fear responses (but without the negative activations) when fear was indexed using fearpotentiated startle rather than amygdala activation (Baskin-Sommers et al., 2011).

\section{The role of LPFC activation and top-down attention on amygdala activation in psychopathy}

In light of compelling evidence that top-down focus of attention limits crucial information processing and moderates the core deficits in psychopathy, there is a need to characterize the neurological underpinnings of the attention bottleneck in psychopathy. Thus, we examined regions in prefrontal cortex that were associated with psychopathy-related differences in response to bottom-up threat cues after attention was allocated to goal-directed stimuli. Consistent with the attention bottleneck model, psychopathy was associated with differential activation of the left LPFC under conditions that established an alternative focus of attention before presenting threat-relative stimuli (i.e., in the early alternative focus condition). In contrast, in the face of salient task-irrelevant threat cues, controls exhibited weaker left LPFC activation. Further supporting the potential importance of left LPFC for the attention bottleneck and its potential impact on threat processing in psychopathy, follow-up analyses revealed that the inverse relationship between LPFC and amygdala activation was significantly greater for psychopaths than nonpsychopaths. Importantly, the association between psychopathy and reduced amygdala activation was completely mediated by activation in left LPFC, particularly BA 47, a region of mid-ventrolateral PFC (mVLPFC; Petrides, 2005).

LPFC has been broadly implicated in selective attention (Badre, Poldrack, Pare-Blagoev, Insler, \& Wagner, 2005; Bishop, Duncan, Brett, \& Lawrence, 2004; Corbetta \& Shulman, 2002; Miller \& Cohen, 2001; Rossi, Pessoa, Desimone, \& Ungerleider, 2009), including selection of task-relevant information (Bode \& Haynes, 2009; Desimone \& Duncan, 1995; Duncan, 2006). Of particular relevance for the present work, regions of left LPFC have been identified as the source of an information-processing bottleneck, in which interference occurs when individuals attempt to complete multiple tasks (Dux et al., 2006). Interpreted in this light and consistent with the Baskin-Sommers et al. (2011) proposal, the enhanced left LPFC activation evident in psychopathic offenders may be related to a more pronounced bottleneck in processing multiple streams of information, particularly when one set of information is directly relevant to goalrelevant task demands and another is not. For psychopaths, this bottleneck appears to enhance their resistance to distraction, but at the cost of processing secondary and peripheral information that may be crucial for regulating maladaptive responses.

The specificity of the increased psychopathy-related LPFC activation to mVLPFC and BA 47 in particular, is consistent with previous work which identifies the mVLPFC as critical for active selection and maintenance of stimuli requiring further processing (Bunge, 2004; Burgess \& Braver, 2010; Hampshire, Duncan, \& Owen, 2007; Petrides, 2005). Importantly, BA 47 is recruited to support stimulus-driven orienting, but only for stimuli relevant for the ongoing task, not for task-irrelevant cues (Hampshire et al., 2007; Kincade, Abrams, Vastafiev, Shulman, \& Corbetta, 2005; Natale, Marzi, \& Macaluso, 2009). This portion of LPFC is also recruited when multiple attributes of a stimulus compete for attentional resources and task demands necessitate selection of a specific attribute (Hedden \& Gabrieli, 2010; Nelson, Reuter-Lorenz, Sylvester, Jonides, \& Smith, 2003). Left mVLPFC has also been found to play a causal role in minimizing interference of distracting task-irrelevant 
information to meet task demands (Wais, Kim, \& Gazzaley, 2012). Indeed, individuals who are faster at resolving interference from competing stimulus attributes exhibit greater activation in BA 47 (Egner, 2011). These findings indicate that this portion of LPFC serves to enhance attentional engagement with goal-directed stimuli for the purpose of selecting the most relevant information in a given context.

Thus, mVLPFC, and BA 47 specifically, has been implicated in processes consistent with our interpretation that psychopaths show greater LPFC activation during the Early Alternative Focus condition because of enhanced goal-directed allocation of attention (i.e., the case of the letter) in the face of salient task-irrelevant information (i.e., the red box threat cue). Assuming this region is important for proactive attentional control and maintenance of task-relevant response sets, disruption of activation in this region may allow for bottom-up processes, including diversion of attention to task-irrelevant salient stimuli, to take precedence. In contrast, psychopaths, who show greater activation of BA 47 when confronted with a competing and salient task-irrelevant stimulus, show reduced bottom-up interference effects, as indexed by decreased amygdala activation to the distracting threat cue. Thus, these data suggest that psychopaths are predisposed to focus on primary goals and tasks to the exclusion of goalirrelevant information, and that this exaggerated selective attention may be mediated by the mVLPFC. More broadly, this pattern of attention selection is consistent with behavioral work indicating that psychopaths are often superior in ignoring distractors and other task-irrelevant information (Hiatt, Schmitt, \& Newman, 2004;

Newman, Schmitt, \& Voss, 1997; Zeier, Maxwell, \& Newman, 2009). In light of this dynamic, psychopathic individuals are prone to display an imbalance of selective attention that favors proximal top-down priorities over potentially relevant but unexpected considerations that modulate the goal-directed behavior of others (see MacCoon, Wallace, \& Newman, 2004 for more detail).

The overall pattern of results, particularly those from the present study, leads us to propose that abnormal selective attention in psychopathy stems from "top-down" LPFC mediation of attention during goal-directed behavior. First, psychopaths' deficit in threat-related amygdala activation was found only during the condition where attention was already engaged in a goal-directed task, highlighting the specific role of a top-down focus of attention in revealing the psychopath's deficit. Second, mVLPFC mediated the inverse relationship between psychopathy and amygdala activation. That is, after controlling statistically for the influence of mVLPFC on amygdala activation, psychopathy-related differences in amygdala activation were no longer significant. Finally, as already noted (Newman \& Baskin-Sommers, 2011), psychopaths' excessive selective attention is evident with non-emotional as well emotional distractors, further reducing the likelihood that psychopathy-related differences in LPFC activation reflect an emotion-specific deficiency in bottom-up activation. Such evidence provides compelling support for the attention bottleneck model of psychopathy. However, it should be noted that while the current study supported our a priori hypotheses regarding the specific influence of attention-related limitations on emotion processing in psychopathy, others have proposed that attention abnormalities in psychopathy and differences in LPFC activation are an indirect consequence of deficiencies in "bottom-up" amygdala-related processes (Blair \& Mitchell, 2009; Kiehl, 2006). For example, models by Moul and colleagues (2012) and Blair (Blair \& Mitchell, 2009) suggest that deficient amygdala functioning may account for most of the extant observations of impaired attention-emotion interactions, particularly given that the subcomponents of the amygdala are related to attentional selection (e.g., basolateral nuclei of the amygdala; Moul et al., 2012). Thus, further research is needed to characterize the precise contributions of top-down versus bottom-up processes of attention and emotion, and also to understand how these processes operate in different indices of psychopathy (e.g., callousunemotional traits versus psychopathy). 


\section{Limitations}

While the findings provide strong support for attentional moderation of neural circuitry underlying threat processing, there are a number of limitations to the present study to be noted. First, in light of research indicating that laboratory findings among European American offenders often do not generalize to African American offenders (BaskinSommers, Newman, Sathasivam, \& Curtin, 2010), the sample was limited to adult Caucasian prisoners. The sample also consists solely of male prisoners. In general, the homogenous nature of the sample may limit generalizability to other populations, including younger individuals with traits on the psychopathy spectrum. Also, six participants (9\% of the sample) were dropped due to excessive movement. While this is a relatively large portion of the sample it is consistent with other studies in which we have administered electrical stimulation (Balderston, Schultz, \& Helmstetter, 2011). Lastly, the sample size is somewhat modest; but results were consistent with hypotheses and power appears to be sufficient to detect group differences.

\section{Conclusions}

Challenging the long-standing view that psychopathy involves a core amygdala-mediated deficit in threat and other emotion processing (Blair, 2007; Lykken, 1995; Patrick, 2007), this study provides strong evidence that psychopaths' amygdala-mediated fear deficit appears and disappears as a function of attention-related priorities. Moreover, the data suggest that psychopaths' failure to recruit the amygdala in response to salient emotion cues while pursuing immediate goals may be a manifestation of a more general LPFC-

instantiated attention bottleneck that severely limits the processing of potentially important peripheral information (Newman \& Baskin-Sommers, 2011). The existence of such an early attention bottleneck that undermines the processing of emotion and inhibitory stimuli could provide a compelling explanation for psychopaths' chronically dysregulated behavior, including their callous disregard for the rights and well-being of others (Newman \& Lorenz, 2003). Moreover, to the extent that psychopaths' core information processing deficits are moderated by attention, rather than absolute (Newman \& Baskin-Sommers, 2011), it may be possible to reduce their antisocial behavior and improve their self-regulation using newly developed methods for training attention (Baskin-Sommers \& Newman, in press; Browning, Holmes, Murphy, Goodwin, \& Harmer, 2010).

\section{Supplementary Material}

Refer to Web version on PubMed Central for supplementary material.

\section{Acknowledgments}

Supported by a grant from the University of Wisconsin-Madison/University of Wisconsin-Milwaukee IRIGP and NIMH grants MH053041 (Newman), NIMH MH070539 (Kiehl), NIDA DA026505 (Kiehl), MH086809 (Larson), and T32-MH018931 (Baskin-Sommers). We wish to thank the Wisconsin Department of Corrections, and especially Dr. Kevin Kallas and Deputy Warden Tom Nickel, for making this research possible.

\section{References}

Aiken, LS.; West, SG. Multiple regression: Testing and interpreting interactions. Newbury Park: Sage; 1991.

Arnett PA, Smith SS, Newman JP. Approach and avoidance motivation in psychopathic criminal offenders during passive avoidance. Journal of Personality and Social Psychology. 1997; 72(6): 1413-1428. [PubMed: 9177023] 
Badre D, Poldrack RA, Pare-Blagoev EJ, Insler RZ, Wagner AD. Dissociable controlled retrieval and generalized selection mechanisms in ventrolateral prefrontal cortex. Neuron. 2005; 47(6):907-918. [PubMed: 16157284]

Balderston NL, Schultz DH, Helmstetter FJ. The human amygdala plays a specific role in the detection of novelty. Neuroimage. 2011; 55(4):1889-1898. [PubMed: 21256226]

Baskin-Sommers AR, Curtin JJ, Newman JP. Specifying the attentional selection that moderates the fearlessness of psychopathic offenders. Psychological Science. 2011; 22(2):226-234. [PubMed: 21245494]

Baskin-Sommers, AR.; Newman, JP. Differentiating the cognition-emotion interactions that characterize psychopathy versus externalizing disorders. In: Robinson, M.; Harmon-Jones, E.; Watkins, E., editors. Cognition and Emotion. New York: Guilford; in press

Baskin-Sommers AR, Newman JP, Sathasivam N, Curtin JJ. Evaluating the generalizability of a fear deficit in African American offenders. Journal of Abnormal Psychology. 2010; 120(1):71-78. [PubMed: 21038928]

Birbaumer N, Veit R, Lotze M, Erb M, Hermann C, Grodd W, Flor H. Deficient fear conditioning in psychopathy: a functional magnetic resonance imaging study. Archives of General Psychiatry. 2005; 62(7):799-805. [PubMed: 15997022]

Bishop SJ. Neurocognitive mechanisms of anxiety: an integrative account. Trends in Cogntiive Science. 2007; 11(7):307-316.

Bishop SJ, Duncan J, Brett M, Lawrence AD. Prefrontal cortical function and anxiety: controlling attention to threat-related stimuli. Nature Neuroscience. 2004; 7(2):184-188.

Bishop SJ, Jenkins R, Lawrence AD. Neural processing of fearful faces: Effects of anxiety are gated by perceptual capacity limitations. Cerebral Cortex. 2007; 17(7):1595-1603. [PubMed: 16956980]

Blair RJ. Neurobiological basis of psychopathy. British Journal of Psychiatry. 2003; 182:5-7. [PubMed: 12509310]

Blair RJ. The amygdala and ventromedial prefrontal cortex in morality and psychopathy. Trends in Cogntiive Science. 2007; 11(9):387-392.

Blair RJ, Mitchell DG. Psychopathy, attention and emotion. Psychological Medicine. 2009; 39(4):543555. [PubMed: 18700991]

Bode S, Haynes JD. Decoding sequential stages of task preparation in the human brain. Neuroimage. 2009; 45(2):606-613. [PubMed: 19111624]

Browning M, Holmes EA, Murphy SE, Goodwin GM, Harmer CJ. Lateral prefrontal cortex mediates the cognitive modification of attentional bias. Biological Psychiatry. 2010; 67(10):919-925. [PubMed: 20034617]

Bunge SA. How we use rules to select actions: a review of evidence form cognitive neuroscience. Cognitive, Affective, \& Behavioral Neuroscience. 2004; 4(4):564-579.

Burgess GC, Braver TS. Neural mechanisms of interference control in working memory: Effects of interference expectancy and fluid intelligence. PLoS ONE. 2010; 5(9):e12861. [PubMed: 20877464]

Carre JM, Hyde LW, Neumann CS, Viding E, Hariri AR. The neural signatures of distinct psychopathic traits. Social Neuroscience. 2012; 8(2):122-135. [PubMed: 22775289]

Cleckley, H. The mask of sanity: An attempt to reinterpret the so-called psychopathic personality. St. Louis, MO: Mosby; 1941.

Cohen, J.; Cohen, P. Applied multiple regression/correlation analysis for the behavioral sciences, Second Ed. Hillsdale, NJ: Lawrence Erlbaum Associates; 1983.

Corbetta M, Patel G, Shulman GL. The reorienting system of the human brain: from environment to theory of mind. Neuron. 2008; 58(3):306-324. [PubMed: 18466742]

Corbetta M, Shulman GL. Control of goal-directed and stimulus-driven attention in the brain. Nature Reviews Neuroscience. 2002; 3(3):201-215.

Cox RW. AFNI: software for analysis and visualization of functional magnetic resonance neuroimages. Computers in Biomedical Research. 1996; 29(3):162-173.

Davidson RJ. Affective style, psychopathology, and resilience: Brain mechanisms and plasticity. American Psychologist. 2000; 55:1196-1214. [PubMed: 11280935] 
Davis M, Falls WA, Campeau S, Kim M. Fear-potentiated startle: a neural and pharmacological analysis. Behavioral and Brain Research. 1993; 58(1-2):175-198.

Desimone R, Duncan J. Neural mechanisms of selective visual attention. Annual Review of Neuroscience. 1995; 18:193-222.

Dolcos F, McCarthy G. Brain systems mediating cognitive interference by emotional distraction. Journal of Neuroscience. 2006; 26(7):2072-2079. [PubMed: 16481440]

Driver J. A selective review of selective attention research from the past century. British Journal of Psychology. 2001; 92(Part 1):53-78.

Duncan J. EPS Mid-Career Award 2004: brain mechanisms of attention. Quarterly Journal of Experimental Psychology. 2006; 59(1):2-27.

Dux PE, Ivanoff J, Asplund CL, Marois R. Isolation of a central bottleneck of information processing with time-resolved FMRI. Neuron. 2006; 52(6):1109-1120. [PubMed: 17178412]

Egner T. Right ventrolateral prefrontal cortex mediates individual differences in conflict-driven cognitive control. Journal of Cognitive Neuroscience. 2011; 23(12):3903-3913. [PubMed: 21568631]

Glenn AL, Raine A, Schug RA. The neural correlates of moral decision-making in psychopathy. Molecular Psychiatry. 2009; 14(1):5-6. [PubMed: 19096450]

Grillon C, Ameli R, Goddard A, Woods SW, Davis M. Baseline and fear-potentiated startle in panic disorder patients. Biological Psychiatry. 1994; 35(7):431-439. [PubMed: 8018793]

Hampshire A, Duncan J, Owen AM. Selective tuning of the blood oxygenation level-dependent response during simple target detection dissociates human frontoparietal subregions. The Journal of Neuroscience. 2007; 27(23):6219-6223. [PubMed: 17553994]

Haprur TJ, Hare RD. Assessment of psychopathy as a function of age. Journal of Abnormal Psychology. 1994; 103(4):604-609. [PubMed: 7822561]

Hare RD. Psychopathy: A clinical construct whose time has come. Criminal Justice and Behavior. 1996; 23(1):25-54.

Hare, RD. Manual for Revised Psychopathy Checklist. Toronto, ON, Canada: Multi-Health Systems; 2003.

Hare RD, Harpur TJ, Hakistan AR, Forth AE, Hart SD, Newman JP. The revised Psychopathy Checklist: Reliability and factor structure. Psychological Assessment: A Journal of Consulting and Clinical Psychology. 1990; 2(3):338-341.

Harenski CL, Harenski KA, Shane MS, Kiehl KA. Aberrant neural processing of moral violations in criminal psychopaths. Journal of Abnormal Psychology. 2010; 119:863-874. [PubMed: 21090881]

Hart SD, Hare RD. Discriminant validity of the Psychopathy Checklist in a forensic psychiatric population. Psychological Assesment. 1989; 1:211-218.

Hedden T, Gabrieli JDE. Shared and selective neural correlates of inhibition, facilitation, and shifting processes during executive control. Neuroimage. 2010; 51:421-431. [PubMed: 20123030]

Hiatt KD, Schmitt WA, Newman JP. Stroop tasks reveal abnormal selective attention among psychopathic offenders. Neuropsychology. 2004; 18(1):50-59. [PubMed: 14744187]

Hsu S-M, Pessoa L. Dissociable effects of bottom-up and top-down factors in the processing of unattended fearful faces. Neuropsychologia. 2007; 45(13):3075-3086. [PubMed: 17631362]

Kiehl KA. A cognitive neuroscience perspective on psychopathy: evidence for paralimbic system dysfunction. Psychiatry Research. 2006; 142(2-3):107-128. [PubMed: 16712954]

Kiehl KA, Smith AM, Hare RD, Mendrek A, Forster BB, Brink J, Liddle PF. Limbic abnormalities in affective processing by criminal psychopaths as revealed by functional magnetic resonance imaging. Biological Psychiatry. 2001; 50(9):677-684. [PubMed: 11704074]

Kincade JM, Abrams RA, Vastafiev SV, Shulman GL, Corbetta M. An event-related functional magnetic resonance imaging study of voluntary and stimulus-driven orienting of attention. The Journal of Neuroscience. 2005; 25(18):4593-4604. [PubMed: 15872107]

Koenigs M, Baskin-Sommers A, Zeier J, Newman JP. Investigating the neural correlates of psychopathy: a critical review. Molecular Psychiatry. 2011; 16(8):792-799. [PubMed: 21135855]

Lavie N, Hirst A, de Fockert JW, Viding E. Load theory of selective attention and cognitive control. Journal of Experimental Psychology: General. 2004; 133(3):339-354. [PubMed: 15355143] 
Lykken, DT. The Antisocial Personalities. Lawrence Erlbaum Associates, Inc; 1995.

MacCoon, DG.; Wallace, JF.; Newman, JP. The context-appropriate allocation of attentional capacity to dominant and non-dominant cues. In: Baumeister, RF.; Vohs, KD., editors. Handbook of SelfRegulation: Research Theory, Application. New York, NY: Guilford Press; 2004. p. 422-466.

Marsh AA, Cardinale EM. When psychopathy impairs moral judgments: neural responses during judgments about causing fear. Social, Cognitive, and Affective Neuroscience. in press

Marsh AA, Finger EC, Fowler KA, Jurkowitz IN, Schechter JC, Yu HH, Blair RJR. Reduced amygalaorbitofrontal connectivity during moral judgments in youths with distruptive behavior disorders and psychopathic traits. Psychiatry Research. 2011; 194:279-286. [PubMed: 22047730]

Mechias M-L, Etkin A, Kalisch R. A meta-analysis of instructed fear studies: Implications for conscious appraisal of threat. Neuroimage. 2010; 49:1760-1768. [PubMed: 19786103]

Miller EK, Cohen JD. An integrative theory of prefrontal cortex function. Annual Review of Neuroscience. 2001; 24:167-202.

Moul C, Killcross S, Dadds MR. A model of differential amygdala activation in psychopathy. Psychological Review. 2012; 119(4):789-806. [PubMed: 22800411]

Muller JL, Sommer M, Wagner V, Lange K, Taschler H, Roder CH, Hajak G. Abnormalities in emotion processing within cortical and subcortical regions in criminal psychopaths: evidence from a functional magnetic resonance imaging study using pictures with emotional content. Biological Psychiatry. 2003; 54(2):152-162. [PubMed: 12873805]

Natale E, Marzi CA, Macaluso E. fMRI correlates of visuo-spatial reorienting investigated with an attention shifting double-cue paradigm. Human Brain Mapping. 2009; 30:2367-2381. [PubMed: 19034897]

Nelson JK, Reuter-Lorenz PA, Sylvester C-YC, Jonides J, Smith EA. Dissociable neural mechanisms underlying response-based and familiarity-based conflict in working memory. Proceedings of the National Academy of Science. 2003; 100(19):11171-11175.

Neumann CS, Hare RD. Psychopathic traits in a large community sample: Links to violence, alcohol use, and intelligence. Journal of Consulting and Clinical Psychology. 2008; 76(5):893-899. [PubMed: 18837606]

Newman, JP.; Baskin-Sommers, A. Early selective attention abnormalities in psychopathy: Implications for self-regulation. In: Posner, MI., editor. Cogntive Neuroscience of Attention. 2nd Edition. New York, NY: Guilford Press; 2011. p. 421-440.

Newman JP, Curtin JJ, Bertsch JD, Baskin-Sommers AR. Attention moderates the fearlessness of psychopathic offenders. Biological Psychiatry. 2010; 67(1):66-70. [PubMed: 19793581]

Newman JP, Kosson DS. Passive avoidance learning in psychopathic and nonpsychopathic offenders. Journal of Abnormal Psychology. 1986; 95(3):252-256. [PubMed: 3745647]

Newman, JP.; Lorenz, AR. Response modulation and emotion processing: Implications for psychopathy and other dysregulatory psychopathology. In: Davidson, RJ.; Scherer, K.; Goldsmith, HH., editors. Handbook of Affective Sciences. Oxford: Oxford University Press; 2003. p. 422-446.

Newman JP, Schmitt WA, Voss WD. The impact of motivationally neutral cues on psychopathic individuals: assessing the generality of the response modulation hypothesis. Journal of Abnormal Psychology. 1997; 106(4):563-575. [PubMed: 9358687]

Ochsner KN, Ray RD, Cooper JC, Robertson ER, Chopra S, Gabrieli JDE, Gross JJ. For better or for worse: neural systems supporting the cognitive down- and up-regulation of negative emotion. Neuroimage. 2004; 23:483-499. [PubMed: 15488398]

Passamonti L, Fairchild G, Goodyer IM, Hurford G, Hagan CC, Rowe JB, Calder AJ. Neural abnormalities in early-onset conduct disorder. Archives of General Psychiatry. 2010; 67(7):729738. [PubMed: 20603454]

Patrick CJ. Emotion and psychopathy: Startling new insights. Psychophysiology. 1994; 31(4):319330. [PubMed: 10690912]

Patrick, CJ. Getting to the heart of psychopathy. In: Herve, H.; Yuille, JC., editors. The psychopath: Theory, research, and social implications. Hillsdale, NJ: Erlbaum; 2007. p. 207-252. 
Patterson CM, Newman JP. Reflectivity and learning from aversive events: toward a psychological mechanism for the syndromes of disinhibition. Psychological Review. 1993; 100(4):716-736. [PubMed: 8255955]

Pessoa L, Padmala S, Morland T. Fate of unattended fearful faces in the amygdale is determined by both attentional resources and cognitive modulation. Neuroimage. 2005; 28:249-255. [PubMed: 15993624]

Petrides M. Lateral prefrontal cortex: architectonic and functional organization. Philosophical Transactions of the Royal Society B. 2005; 360:781-795.

Preacher KJ, Hayes AF. SPSS and SAS procedures for estimating indirect effects in simple mediation models. Behavior Research Methods, Instruments, and Computers. 2004; 36:717-731.

Preacher KJ, Hayes AF. Asymptotic and resampling strategies for assessing and comparing indirect effects in multiple mediator models. Behavior Research Methods. 2008; 40:879-891. [PubMed: 18697684]

Rilling JK, Glenn AL, Jairam MR, Pagnoni G, Goldsmith DR, Elfenbein HA, Lilienfeld SO. Neural correlates of social cooperatin and non-cooperation as a function of psychopathy. Biological Psychiatry. 2007; 61:1260-1271. [PubMed: 17046722]

Rossi AF, Pessoa L, Desimone R, Ungerleider LG. The prefrontal cortex and the executive control of attention. Experimental Brain Research. 2009; 192(3):489-497. [PubMed: 19030851]

Sadeh N, Verona E. Psychopathic traits associated with abnormal selective attention and impaired cognitive control. Neuropsychology. 2008; 22:669-680. [PubMed: 18763886]

Siegle GJ, Steinhauer SR, Thase ME, Stenger VA, Carter CS. Can't Shake that Feeling: fMRI Assessment of Sustained Amygdala Activity in Response to Emotional Information in Depressed Individuals. Biological Psychiatry. 2002; 51:693-707. [PubMed: 11983183]

Singh-Manoux A, Kivimaki M, Glymour MM, Elbaz A, Berr C, Ebmeier KP, Dugravot A. Timing of onset of cognitive decline: Results from Whitehall II prospective cohort study. British Medical Journal. 2012; 344:d7622. [PubMed: 22223828]

Viding E, Sebastian CL, Dadds MR, Lockwood P, Cecil C, DeBrito S, McCrory E. Amygdala response to pre-attentive masked fear is associated with callous-unemotional traits in children with conduct problems. American Journal of Psychiatry. 2012; 169(10):1109-1116. [PubMed: 23032389]

Wais PE, Kim OY, Gazzaley A. Distractibility during episodic retrieval is exacerbated by perturbation of left ventrolateral prefrontal cortex. Cerebral Cortex. 2012; 22:717-724. [PubMed: 21680847]

White SF, Marsh AA, Fowler KA, Schechter JC, Adalio C, Pope K, Blair RJ. Reduced amygdala response in youths with disruptive behavior disorders and psychopathic traits: decreased emotional response versus increased top-down attention to nonemotional features. American Journal of Psychiatry. 2012; 169(7):750-758. [PubMed: 22456823]

Zachary, RA. Shipley Institute of Living Scale: Revised Manual. Los Angeles, CA: Western Psychological Service; 1986.

Zeier JD, Maxwell JS, Newman JP. Attention moderates the processing of inhibitory information in primary psychopathy. Journal of Abnormal Psychology. 2009; 118(3):554-563. [PubMed: 19685952] 
A. Early Alternative Focus

\section{n}

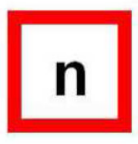

B. Late Alternative Focus

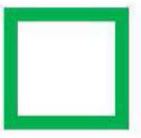

\section{$\mathbf{N}$}

C. Late Threat Focus
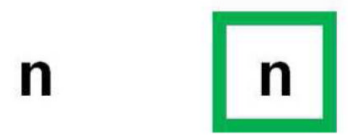

$\operatorname{Red}$
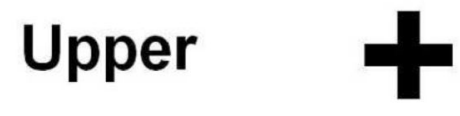

Match

\section{Early Threat Focus}

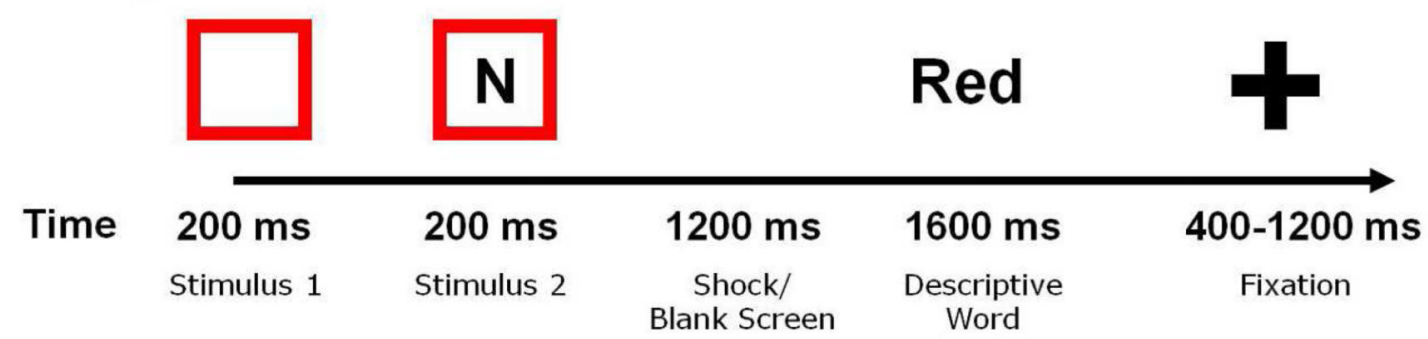

Figure 1.

Schematic of task. The instructed fear task consisted of four conditions in which focus of attention and timing of attentional focus was manipulated: (A) Early Alternative Focus, (B) Late Alternative Focus, (C) Late Threat Focus, and (D) Early Threat Focus. During Threat Focus participants attended to the color of a box predicting shock administration (red = potential shock, green $=$ safe). For Alternative Focus, participants were instructed to attend to the case of a letter stimulus. In each trial the box (red or green) and letter (uppercase "N" or lowercase "n"), were presented sequentially with the order varying according to condition. During Early trials the stimulus to be attended to was presented first and during Late trials it was presented second. Shocks were presented during the last $200 \mathrm{~ms}$ of the blank screen on $20 \%$ of potential threat trials. Finally, participants pressed a button indicating whether a probe word, "red" or "green" for Threat Focus and "Upper or "Lower" for Alternative Focus matched the stimulus presented during that trial. 


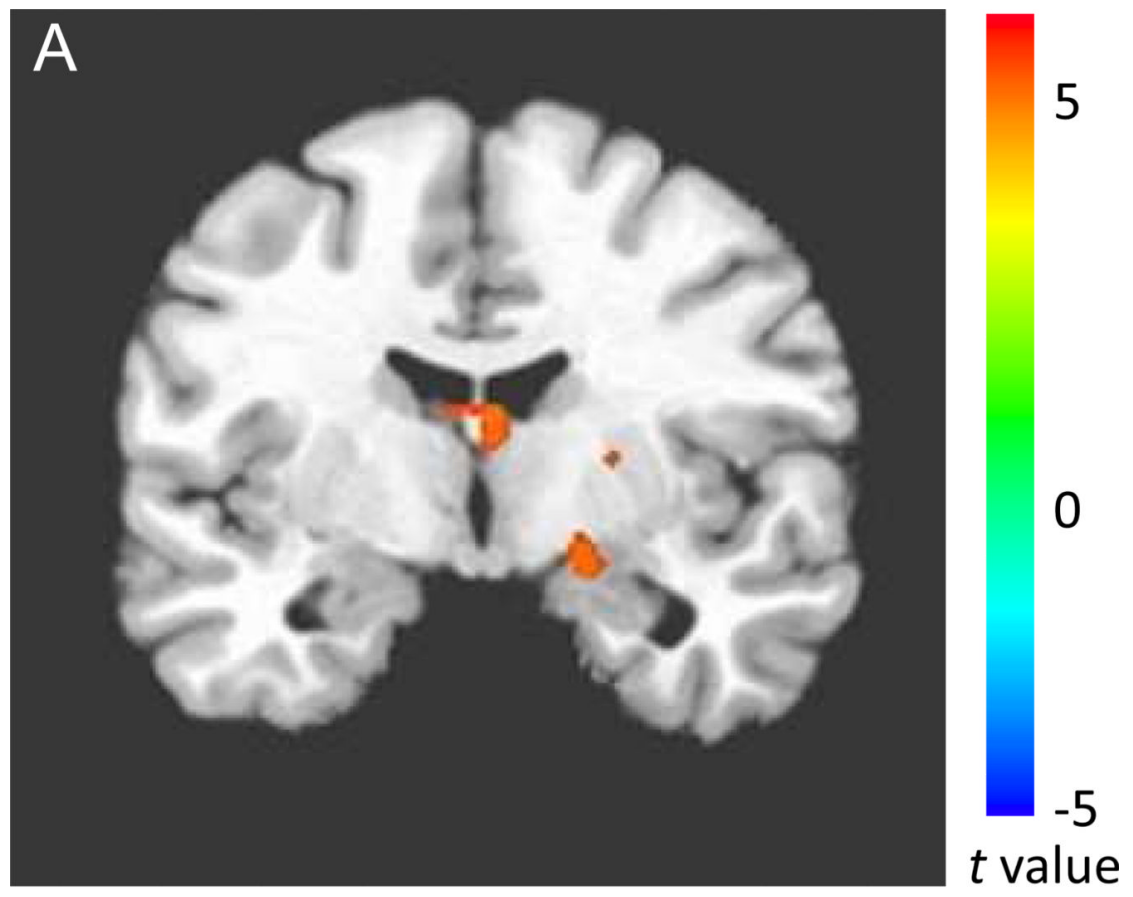

\section{B}

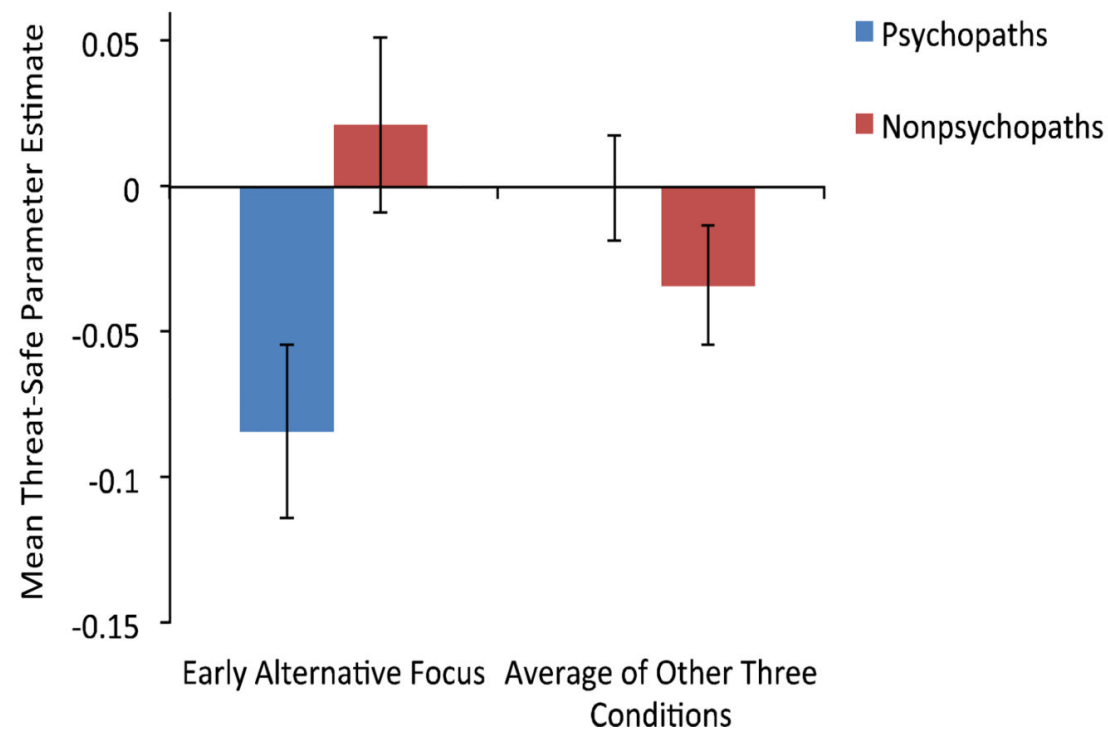

Figure 2.

Results of paired comparisons demonstrating decreased activation of the right amygdala and extended amygdala to threat among psychopaths only when attention is previously engaged by another task. (A) The brain image depicts a significant Group X Condition interaction for the Early Alternative Focus compared to the average of the three remaining conditions $(\mathrm{y}=$ -6). (B) The bar graph depicts mean threat minus safe percent signal change for each condition based on the right amygdala cluster demonstrating a significant group difference for the Early Alternative Focus condition. Error bars represent standard error of the mean. As can be seen, during Early Alternative Focus trials decreased activation in psychopaths compared to nonpsychopaths was present in the right amygdala. 

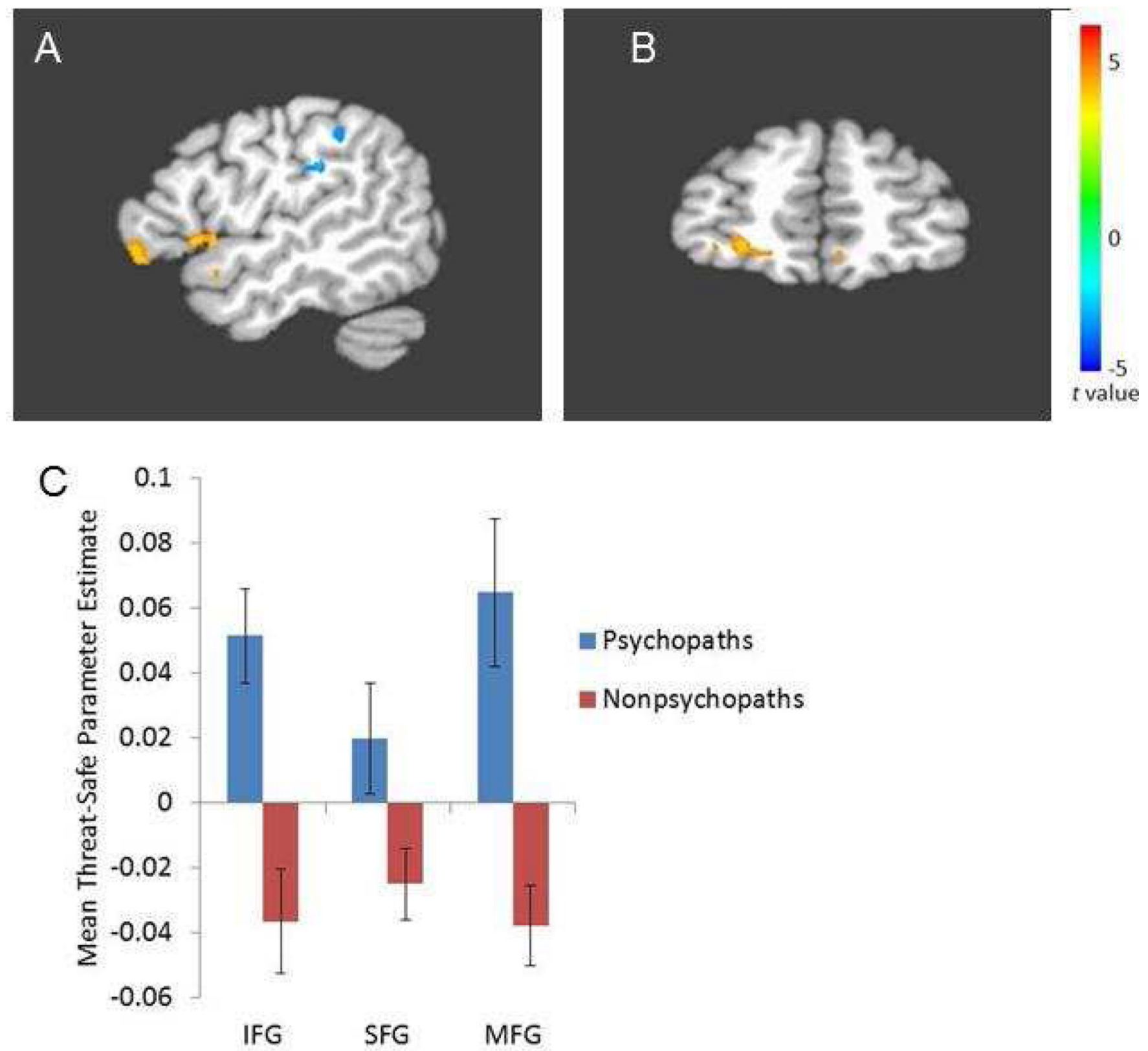

Figure 3.

LPFC group differences and relations with amygdala activation for the Early Alternative Focus condition. The brain images (A, B) and bar graph (C) present group differences in left LPFC activation from a voxel-wise t-test (orange indicates greater activation in psychopaths compared to nonpsychopaths). Greater activation for psychopaths compared to nonpsychopaths is present in (A) the IFG ( $\mathrm{x}=-49, \mathrm{y}=14, \mathrm{z}=0$; BA 47), MFG ( $\mathrm{x}=-49, \mathrm{y}$ $=36, \mathrm{z}=-4$; BA 47), and (B) SFG $(\mathrm{x}=-23, \mathrm{y}=48, \mathrm{z}=-3$; BA 10). Error bars in the bar graph $(\mathrm{C})$ represent standard error of the mean. 

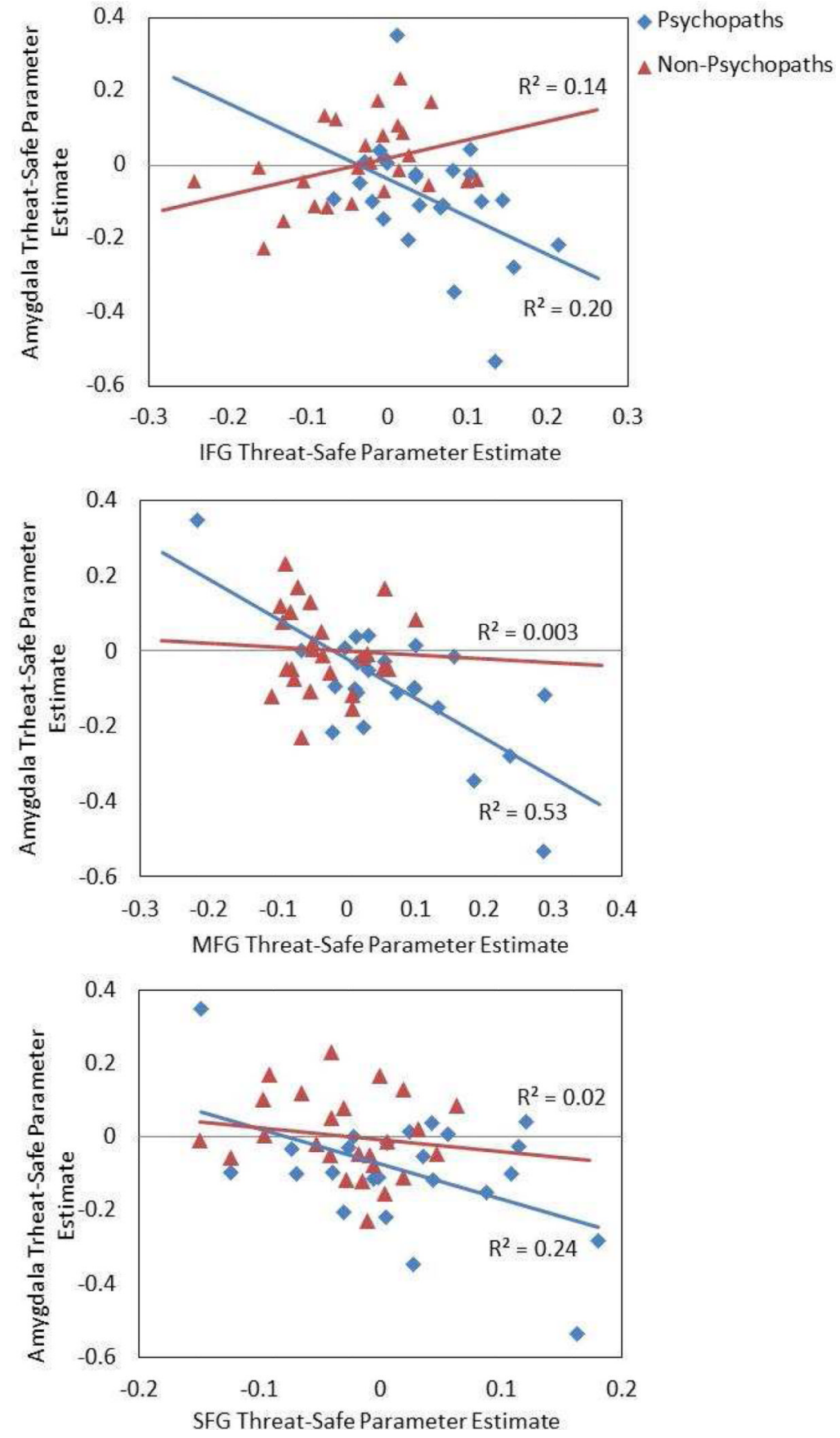

Figure 4.

Correlations between LPFC and amygdala for Early Alternative Focus. The scatterplots depict simple regressions predicting amygdala activation with the mVLPFC/BA 47 (IFG, MFG), and the dorsolateral PFC (SFG) for the Early Alternative Focus condition separately for both groups. Correlations between PFC regions and the amygdala were significant for the psychopaths (all $p$ 's $<.05$ ), but not significant for non-psychopaths (all $p$ 's $>.05$ ). 
Table 1

Means and standard deviations for relevant descriptive variables.

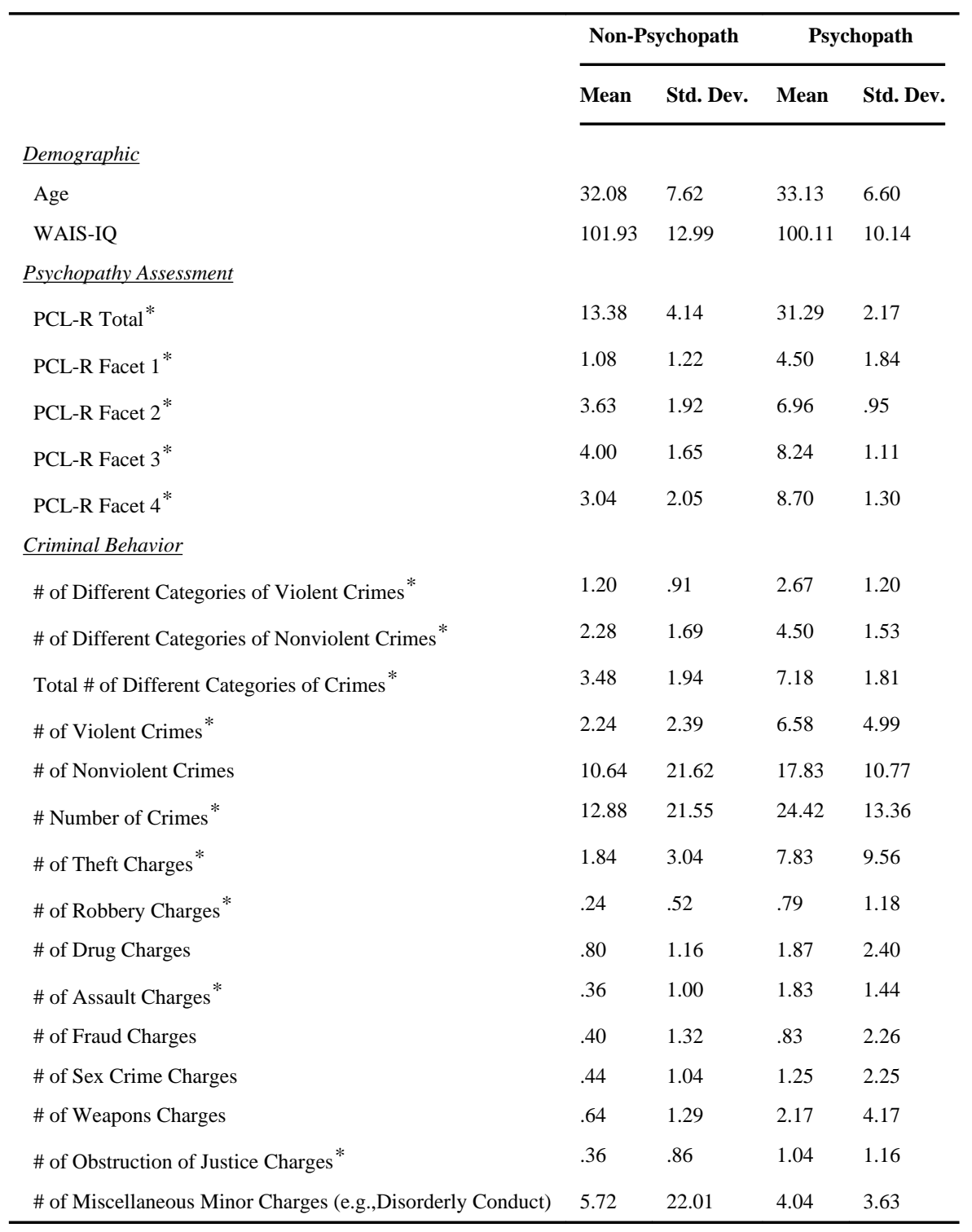

Note: WAIS-IQ= Wechsler Adult Intelligence Scale; PCL-R= Psychopathy Checklist-Revised

Flagged cells indicate a significant $(\mathrm{p}<.05)$ difference between groups. 
Table 2

Mean BOLD signal for amygdala cluster presented separately for safe (green box) and threat (red box) trials for each of the four attention focus conditions.

\begin{tabular}{|c|c|c|c|}
\hline & & Psychopaths & Nonpsychopaths \\
\hline \multirow[t]{2}{*}{ Early Alternative } & Threat & $-.108(.29)^{*}$ & $-.023(.45)$ \\
\hline & Safe & $-.010(.32)$ & $-.022(.46)$ \\
\hline \multirow{2}{*}{ Late Alternative } & Threat & $.046(.34)$ & $-.095(.24)$ \\
\hline & Safe & $.016(.19)$ & $-.069(.20)$ \\
\hline \multirow[t]{2}{*}{ Late Threat } & Threat & $-.158(.30)$ & $-.071(.31)$ \\
\hline & Safe & $-.152(.29)$ & $-.074(.30)$ \\
\hline \multirow[t]{2}{*}{ Early Threat } & Threat & $.034(.34)$ & $-.084(.26)^{*}$ \\
\hline & Safe & $.015(.34)$ & $.034(.25)$ \\
\hline
\end{tabular}

Note: Asterisks $(*)$ indicate significant pairwise differences $(p<.05)$ between threat and safe conditions within a group. There were no significant between group differences for when tested separately for threat and safe for each of the four attentional focus conditions. 